\title{
sciendo
}

\author{
Current Issues in Pharmacy and Medical Sciences
}

Formerly ANNALES UNIVERSITATIS MARIAE CURIE-SKIODOWSKA, SECTIO DDD, PHARMACIA

journal homepage: http://www.curipms.umlub.pl/

\section{Treatment modality, diabetic control and blood homeostasis in type 2 diabetes mellitus patients in Basra}

\author{
Sheima N. Kadhim ${ }^{1} \oplus$, Asia S. Abdullah ${ }^{1 \star}{ }^{\circledR}$, Ahmed I. Sabah $^{2}$ \\ ${ }^{1}$ Department of Pharmacology and Toxicology, Institute of Pharmacy, Basra, Iraq \\ 2 Department of Medicine, Al-Mawanee General Hospital, Basra, Iraq
}

\section{ARTICLE INFO}

Received 18 April 2020

Accepted 15 March 2021

\section{Keywords:}

insulin,

metformin,

prothrombin time (PT),

activated thromboplastin time

(APTT),

T2DM patients.

\begin{abstract}
This study is aimed at investigating the relationship between treatment modality, glycemic control and blood homeostasis as represented by prothrombin time (PT) and activated thromboplastin time (APTT) in T2DM patients. Sixty-four type 2 diabetic patients (40 males and 24 females) on metformin or insulin or both for not less than six months of ages between 20 and 75 years were selected during their visit to Diabetes Endocrine and Metabolism Centers in two General Hospitals in Basra. Socioeconomic characteristics and treatment plans were recorded. Glycated haemoglobin (HbAlc), lipid profiles and hematological parameters measured in blood samples were taken. Lower mean $\mathrm{HbAlc}$ $(p=0.0383)$ was found in patients on metformin alone, higher percentage of hemoglobin was found in patients on insulin treatment, and higher levels of LDL $(\mathrm{P}=0.0018)$ and HDL $(P=0.0241)$ in patients on metformin and insulin. Treatment manner had no effect on mean PT or APTT, however, there was a significant inverse correlation of PT with LDL $(\mathrm{P}=0.0042)$, and a direct correlation of APTT with HbAlc $(\mathrm{p}=0.0209)$ and an inverse correlation of APTT with platelets count $(\mathrm{P}=0.0324)$ in patients on insulin treatment. In addition, there was a significant direct correlation of APTT with triglycerides (TG) $(\mathrm{P}=0.0069)$ in patients on metformin treatment. In conclusion, lower mean of $\mathrm{HbAlc}$ was found only in patients receiving metformin drug alone, higher $\mathrm{Hb}$ percentage were found in patients treated with insulin alone, higher LDL and higher HDL levels were found in patients treated with both metformin and insulin for at least six months. Treatment manner had no effect on mean PT or APTT and further studies are needed to bring about understanding of diabetic control and blood homeostasis.
\end{abstract}

\section{INTRODUCTION}

Worldwide, about 5.0 million people died from diabetes mellitus (DM) in 2015. This corresponds to one death every six seconds [1]. Thrombosis is the main cause of death in patients with DM, indeed, around two thirds of all diabetic patients eventually die from thrombotic diseases [2].

In Iraq, a high rate of incidence of diabetes has been documented. T2DM includes a broad variety of elevated glucose level conditions because of insulin resistance. Comparative deficiencies of insulin secretion and hepatic insulin resistance cause an elevation of gluconeogenesis and a reduction of glycogen synthesis [3]. T2DM is associated with enhanced triglycerides (TG), low-density lipoprotein cholesterol (LDL), C-reactive protein (CRP) and plasminogen activator inhibitor-1 (PAI-1) levels. In addition, it is

\footnotetext{
* Corresponding author

e-mail: asia_abdullah65@yahoo.com
}

accompanied by low high-density lipoprotein cholesterol (HDL) levels [4].

Metformin is an insulin sensitizer belonging to the biguanide class of drugs. It increases the sensitivity of liver and peripheral tissues to insulin and reduces hepatic glucose production. It is commonly used as the first-line treatment for T2DM patients, as previous study has stated that metformin reduces diabetes-associated thrombotic complications [5]. However, whether metformin can prevent thrombosis effectively is unknown - nor is its possible mechanism of action. In addition, whether metformin is effective against thrombosis in both diabetic and non-diabetic individuals is not known.

This study was carried out to estimate the possible effect of long-term use of Metformin or insulin or both on glycemic control and blood homeostasis as represented by prothrombin time (PT) and activated thromboplastin time 
(APTT) in T2DM patients - as APTT and PT, as well as platelet counts are hematological indicators for patient coagulation states [6].

\section{SUBJECTS AND METHODS}

This study was conducted during the period from February to May 2019. Sixty-four type 2 diabetic patients (40 males and 24 females) on metformin or insulin or both for not less than six months and between ages between 20 and 75 years were selected during their visit to the Diabetes Endocrine and Metabolism Centers in two General Hospitals in Basra.

The patients were placed into three groups. The first group (M) consisted of 20 patients on metformin therapy, the second group (MI) consisted of 25 patients on metformin and insulin therapy and the third group (I) was of patients undergoing insulin therapy alone. Patients were excluded from the study if they were type 1 diabetic patients or if they have any cognitive problems. Socioeconomic characteristics and treatment plans were documented. Fasting blood samples were obtained to determine glycated haemoglobin (HbA1c) and lipids profile. In addition, hematological tests (PT, APTT, INR, Hb (\%) and platelets count) were undertaken. Here, HbA1c level of $7 \%$ or less indicates sufficient glycemic control, while HbA1c level of more than $7 \%$ demonstrates a reduced glycemic control - as stated within the American Diabetic Association guidelines [7].

\section{Laboratory investigations}

Glycated hemoglobin (HbA1C) was measured by means of D-10 Dual Program (Bio-Rad Laboratories, Inc., Hercules, CA 94547, 220-020, California; USA). The D-10 Dual Program is based on chromatographic separation of the analytes by ion exchange (HPLC). Patient serum lipid profile (cholesterol, triglycerides, low-density lipoprotein cholesterol (LDL) and high-density lipoprotein cholesterol (HDL) levels) were determined by applying enzymatic methods (Dimension Vista 1500T Intelligent Lab System from Siemens Company-Germany) at the laboratory of biochemistry. PT and APTT were assayed through standard clotting methods by using a BIOLABO Kit (France), according to company instructions.

\section{Statistical analysis}

Statistical analysis was performed by means of GraphPad Prism software (version 7.0, GraphPad Software, Inc., San Diego, CA). Descriptive statistics such as mean \pm standard deviation (SD), were established for all evaluated parameters. ANOVA (and non-parametric analysis) was applied to perform comparison between groups. Pearson's correlation coefficients were used to estimate the associations between variables. Here, $p$ values of less than 0.05 were considered as significantly different.

\section{RESULTS}

Sixty-four type 2 diabetic patients ( 40 males and 24 females) of ages between 20 and 75 years, on metformin or insulin or both for not less than six months were included in this study. Lower mean HbA1c $(p=0.0383)$ was found in the group $\mathrm{M}$ patients (on metformin treatment at least six months). In this group, the dose of metformin ranged between 500 to $1000 \mathrm{mg} /$ day. Higher $\mathrm{Hb}(\%)$ was found in group I patients (on insulin treatment at least six months). Higher LDL $(\mathrm{P}=0.0018)$ and higher HDL $(\mathrm{P}=0.0241)$ levels were noted in the MI group patients (on metformin and insulin treatments at least six months) (Table 1).

Table 1. Measured haematological and biochemical tests (Mean \pm STDEV) of type $2 \mathrm{DM}$ patients in long-term treatment with: metformin only (group M), metformin and insulin (group MI) and Insulin only (group I)

\begin{tabular}{|l|c|c|c|c|}
\hline \multirow{2}{*}{ Variables } & \multicolumn{3}{c|}{ Groups (Mean \pm SD) } & \multirow{2}{*}{ P value } \\
\cline { 2 - 4 } & $\begin{array}{c}\text { M } \\
(n=20)\end{array}$ & $\begin{array}{c}\text { MI } \\
(n=25)\end{array}$ & $\begin{array}{c}\text { I } \\
(n=19)\end{array}$ & \\
\hline Age (years) & $54.2 \pm 7.4$ & $57.4 \pm 9.9$ & $50.9 \pm 18.3$ & 0.2349 \\
\hline Sex (M/F) & $6 / 14$ & $11 / 14$ & $7 / 12$ & \\
\hline HbA1C (\%) & $8.1 \pm 1.5$ & $9.2 \pm 1.7$ & $9.2 \pm 1.4$ & $0.0383 *$ \\
\hline PT (sec) & $14.8 \pm 1.7$ & $14.5 \pm 1.7$ & $15.7 \pm 1.3$ & 0.0677 \\
\hline PTT (sec) & $37.2 \pm 7.0$ & $33.0 \pm 6.5$ & $33.7 \pm 4.5$ & 0.0669 \\
\hline INR & $1.1 \pm 0.2$ & $1.05 \pm 0.07$ & $1.06 \pm 0.1$ & 0.4288 \\
\hline Hb (\%) & $12.1 \pm 1.6$ & $12.4 \pm 1.5$ & $13.3 \pm 1.0$ & $0.0264 *$ \\
\hline Platelets count & $285.8 \pm 68.8$ & $261.9 \pm 88.5$ & $294.9 \pm 65.2$ & 0.3323 \\
\hline Cholesterol & $5.5 \pm 1.1$ & $5.3 \pm 1.2$ & $5.6 \pm 1.5$ & 0.7249 \\
\hline Triglycerides & $3.0 \pm 1.5$ & $3.3 \pm 2.1$ & $3.6 \pm 2.2$ & 0.6372 \\
\hline LDL & $1.5 \pm 0.7$ & $1.9 \pm 0.6$ & $1.3 \pm 0.1$ & $0.0018 * *$ \\
\hline HDL & $1.3 \pm 0.3$ & $2.4 \pm 2.3$ & $1.4 \pm 0.3$ & $0.0241 *$ \\
\hline
\end{tabular}

HbA1c: glycated haemoglobin; PT: prothrombin time; PTT: partial

thromboplastin time; INR: international normalized ratio; $\mathrm{Hb}$ : haemoglobin; LDL: low density lipoprotein; HDL: high density lipoprotein.*, ** Statistically significant values (significance $\mathrm{P}<0.05$ ) (significance $\mathrm{P}<0.05$ )

Treatment manner had no effect on mean PT or APTT, however, there was a significant inverse correlation of PT with LDL $(\mathrm{P}=0.0042)$, direct correlation of APTT with HbA1c $(p=0.0209)$ and inverse correlation of APTT with platelets counts $(\mathrm{P}=0.0324)$ in the third group of patients (on insulin treatment at least six months). In addition, there was a significant direct correlation of APTT with TG $(\mathrm{P}=0.0069)$ in the first group (M) of patients (Table 2).

Table 2. Correlations between PT and PTT with HbAlc, lipid profile and hematologic parameters in type $2 \mathrm{DM}$ patients in long term treatment with: metformin only (group M), metformin and insulin (group MI) and Insulin only (group I)

\begin{tabular}{|l|c|c|c|c|c|c|}
\hline \multirow{4}{*}{} & \multicolumn{3}{|c|}{ PT } & \multicolumn{3}{c|}{ APTा } \\
\cline { 2 - 7 } & $\begin{array}{c}M \\
(n=20)\end{array}$ & $\begin{array}{c}\text { MI } \\
(n=25)\end{array}$ & $\begin{array}{c}\text { I } \\
(n=19)\end{array}$ & $\begin{array}{c}\text { M } \\
(n=20)\end{array}$ & $\begin{array}{c}\text { MI } \\
(n=25)\end{array}$ & $\begin{array}{c}I \\
(n=19)\end{array}$ \\
\hline \multirow{2}{*}{ HbA1c } & $r=-0.05158$ & $r=-0.2667$ & $r=0.09842$ & $r=0.4158$ & $r=-0.102$ & $r=0.5253$ \\
& $p=0.8290$ & $p=0.1975$ & $p=0.6885$ & $p=0.0683$ & $p=0.6275$ & $p=0.0209 *$ \\
\hline \multirow{2}{*}{ Hb } & $r=-0.06573$ & $r=0.05202$ & $r=-0.06543$ & $r=0.1436$ & $r=0.1245$ & $r=0.4282$ \\
& $p=0.7831$ & $p=0.8049$ & $p=0.7901$ & $p=0.5459$ & $p=0.5532$ & $p=0.0674$ \\
\hline \multirow{2}{*}{ Platelets } & $r=-0.1018$ & $r=0.06154$ & $r=0.1807$ & $r=0.2566$ & $r=0.2814$ & $r=-0.492$ \\
& $p=0.6692$ & $p=0.7701$ & $p=0.4592$ & $p=0.2747$ & $p=0.1730$ & $p=0.0324 *$ \\
\hline \multirow{2}{*}{ Cholesterol } & $r=-0.2506$ & $r=0.00264$ & $r=0.2823$ & $r=0.05481$ & $r=-0.1857$ & $r=-0.1205$ \\
& $p=0.2865$ & $p=0.9900$ & $p=0.2416$ & $p=0.8185$ & $p=0.3741$ & $p=0.6231$ \\
\hline \multirow{2}{*}{ TG } & $r=0.1096$ & $r=-0.04515$ & $r=0.05924$ & $r=0.5833$ & $r=-0.4464$ & $r=-0.1268$ \\
& $p=0.6455$ & $p=0.8303$ & $p=0.8096$ & $p=0.0069 *$ & $p=0.8322$ & $p=0.6050$ \\
\hline \multirow{2}{*}{ LDL } & $r=0.2167$ & $r=-0.1893$ & $r=-0.6254$ & $r=-0.1379$ & $r=0.01125$ & $r=-0.2115$ \\
& $p=0.3568$ & $p=0.3648$ & $p=0.0042 *$ & $p=0.5620$ & $p=0.9574$ & $p=0.3847$ \\
\hline \multirow{2}{*}{ HDL } & $r=0.1881$ & $r=-0.1386$ & $r=0.1648$ & $r=-0.2644$ & $r=0.08819$ & $r=-0.2746$ \\
& $p=0.4271$ & $p=0.5089$ & $p=0.5003$ & $p=0.2599$ & $p=0.6751$ & $p=0.2552$ \\
\hline
\end{tabular}

HbA1c: glycated haemoglobin; PT: prothrombin time; PTT: partial thromboplastin time; $\mathrm{Hb}$ : haemoglobin; TG: Triglycerides; LDL: low density lipoprotein; HDL: high density lipoprotein. *Statistically significant values 


\section{DISCUSSION}

This study was designed to investigate the association between treatment modality, glycemic control and blood homeostasis as represented by prothrombin time (PT) and activated thromboplastin time (APTT) in T2DM Iraqi patients receiving metformin or insulin or both. Diabetes mellitus is associated with many complications. Hyperglycemia, increased blood pressure, oxidative stress, dyslipidemia and inflammation are all features of T2DM, and are risk factors in the development of vascular complications [8-11]. Diabetes control helps to decrease the risk of these complications.

Most of the diabetic patients involved in this study were glycemic uncontrolled regardless of which drug treatment used. This study discovered that lower mean of glycated hemoglobin (HbA1c) was more common in patients receiving metformin drug alone, when compared with patients on metformin with insulin or on insulin alone, however, the mean $\mathrm{HbA1c}$ was 8.1, which is still higher than the normal $\mathrm{HbA} 1 \mathrm{c}$ values, and the dose of metformin ranged between 500 to $1000 \mathrm{mg} /$ day.The results also revealed higher $\mathrm{Hb}(\%)$ in patients treated with insulin alone, this result is consistent with a previous study on insulin that noted that insulin analogs alleviate the decline of haemoglobin in diabetic patients with impaired renal function [12].

Furthermore, higher LDL and higher HDL levels was found in patients treated with a combination of metformin and insulin for at least six months, when compared to patients treated with metformin alone or insulin alone. This finding, to the best of our knowledge, is novel.Treatment manner had no effect on mean PT or APTT; however, there was a significant inverse correlation of PT with LDL, direct correlation of APTT with HbA1c and inverse correlation of APTT with platelets counts in patients treated with insulin for at least six months. In addition, there was a significant direct correlation of APTT with TG in patients treated with metformin for at least six months. These findings are consistent with a recent study on the impact of glycemic control on lipid metabolism and coagulation in pregestational (PGDM) and gestational (GDM) diabetes women treated with insulin; they concluded that poor glycemic control influences both lipid profile and the coagulation of blood [13].

Moreover, we found it notable that different types, dosage forms and duration of metformin, insulin and combined drugs used, in addition to the variety of the populations evaluated may determine the effects on hemostasis. Thus, it would be motivating to extend research to non-diabetic patients using metformin, such as patients with polycystic ovary syndrome [14] or patients with obesity [15], to investigate the effect of metformin on blood homeostasis in non-diabetic patients.

\section{CONCLUSION}

Lower mean of $\mathrm{HbA} 1 \mathrm{c}$ was found in patients receiving metformin drug alone, higher $\mathrm{Hb}(\%)$ was noted in patients treated with insulin alone, higher LDL and higher HDL levels was indicated in patients treated with both metformin and insulin for at least six months. Treatment manner had no effect on mean PT or APTT, and further studies are needed to understand the connection between diabetic control and blood homeostasis.

\section{AUTHOR'S CONTRIBUTION}

None.

\section{CONFLICTS OF INTEREST}

The authors declare that they have no conflicts of interest.

\section{DATA AVAILABILITY STATEMENT}

No data used to support this study is available.

\section{FUNDING TESTAMENT}

This research was funded by authors themselves. The authors did not receive any funds for this research.

\section{ORCID iDs}

Sheima Nadim Kadhim (Dhttps://orcid.org/0000-0002-7158-2306 Asia Selman Abdullah (1)https://orcid.org/0000-0002-7384-0313

\section{REFERENCES}

1. da Rocha Fernandes J, Ogurtsova K, Linnenkamp U, Guariguata L, Seuring T, Zhang P, et al. IDF Diabetes Atlas estimates of 2014 global health expenditures on diabetes. Diabetes Res Clin Pract. 2016;117:48-54.

2. Vazzana N, Ranalli P, Cuccurullo C, Davì G. Diabetes mellitus and thrombosis. Thromb Res. 2012;129(3):371-7.

3. Setter SM, Iltz JL, Thams J, Campbell RK. Metformin hydrochloride in the treatment of type 2 diabetes mellitus: a clinical review with a focus on dual therapy. Clin Ther. 2003;25(12):2991-3026.

4. Markowicz-Piasecka M, Huttunen K, Mateusiak L, MikiciukOlasik E, Sikora J. Is metformin a perfect drug? Updates in pharmacokinetics and pharmacodynamics. Curr Pharm Des. 2017;23(17):2532-50.

5. Roussel R, Travert F, Pasquet B, Wilson PW, Smith SC, Goto S, et al. Metformin use and mortality among patients with diabetes and atherothrombosis. Arch Intern Med. 2010;170(21):1892-9.

6. Ambelu YA, Shiferaw MB, Abebe M, Enawgaw B. Prothrombin time, activated partial thromboplastin time and platelet counts of type II diabetes mellitus: a comparative study. J Diabetes Metab Disord. 2018;17(2):117-21.

7. American Diabetes Association. Executive summary: Standards of medical care in diabetes - 2014. Diabetes Care. 2014;37:S5.

8. Boyle PJ. Diabetes mellitus and macrovascular disease: mechanisms and mediators. AJM. 2007;120(9):S12-7.

9. Beckman JA, Creager MA, Libby P. Diabetes and atherosclerosis: epidemiology, pathophysiology, and management. JAMA. 2002;287(19):2570-81.

10. Kumar A, Shanmugasundaram P. Development of a Validated Questionnaire to Assess Attitude of Patient to-wards SelfManagement among uncontrolled diabetic population in Tamil Nadu. IJRPS. 2019;10(2):1089-95.

11. Johny SA, Anupriya AP, John O, Surekha G, Paarakh PM. Evaluation of pharmacoeconomics, medication adherence and quality of life in type 2 diabetes mellitus patients. IJRPS. 2017;8(3):315-20.

12. Hasslacher C, Collenberg E, Möcks J. Effect of insulin analogs on the decline of hemoglobin in diabetic patients with nephropathy. Exp Clin Endocrinol Diabetes. 2010;118(06):341-5.

13. Teliga-Czajkowska J, Sienko J, Zareba-Szczudlik J, MalinowskaPolubiec A, Romejko-Wolniewicz E, Czajkowski K. Influence of glycemic control on coagulation and lipid metabolism in pregnancies complicated by pregestational and gestational diabetes mellitus. Adv Biomed. 2019:81-8. 
14. Practice Committee of the American Society for Reproductive Medicine. Role of metformin for ovulation induction in infertile patients with polycystic ovary syndrome (PCOS): a guideline. Fertility and sterility. 2017;108(3):426-41.
15. Seifarth C, Schehler B, Schneider HJ. Effectiveness of metformin on weight loss in non-diabetic individuals with obesity. Exp Clin Endocrinol Diabetes. 2013;121(01):27-31. 